Diabetologia 10, 421-425 (1974)

(C) by Springer-Verlag 1974

\title{
Glucose-Induced Insulin Release Patterns: Effect of Starvation
}

\author{
G. Fink, R.A. Gutman, J.C. Cresto, H. Selawry, R. Lavine and L. Recant \\ Veterans Administration Hospital and Georgetown University School of Medicine, Washington, D. C., USA
}

Received: January 29, 1974, and in revised form: May 13, 1974

Summary. Continuous glucose infusions over a $60 \mathrm{~min}$ period were carried out in 24 human subjects. A priming dose of $0.33 \mathrm{gm}$ glucose $/ \mathrm{kg}$ was followed by a constant infusion of $20 \mathrm{mg}$ glucose $/ \mathrm{kg} / \mathrm{min}$. The glucose-stimulated insulin release curves were biphasic (Phase I and III) in all subjects. The diabetics, compared with normal controls, showed decreased total insulin release with a greater decrement in phase I. Starvation of normal subjects for $48 \mathrm{~h}$ resulted in decreased insulin release, though Phases I and II were equivalently diminished. Rats were starved for $48 \mathrm{~h}$ and their pancreata studied in the isolated pan- creas perfusion system. Following glucose stimuli, insulin release showed a pattern similar to that of diabetics, namely, decreased total insulin and a greater decrease in phase I than II. It is postulated that this period of starvation for a small animal was far more pronounced than that in man. The altered insulin secretory pattern in prolonged starvation is an additional manifestation of "starvation diabetes" and suggests the possibility of similar defects in starvation and diabetes.

Key words: Insulin patterns, starvation, diabetes.
Glucose stimulates the normal pancreas to release insulin, both in vivo and in vitro, in a biphasic fashion $[1-4]$. The first phase occurs within 3 to 5 min of an intravenous glucose stimulus and is characterized by a sharp peak of insulin release which rapidly declines to approximately $50 \%$ of peak levels despite continuation of the glucose stimulus. This decline lasts 1 to 3 min and then the second phase begins. This phase is characterized by a gradually increasing rate of insulin secretion which lasts as long as the stimulus is continued

In "prediabetic" and diabetic human subjects, Cerasi and Luft showed that the initial rapid phase of glucose stimulated insulin release was diminished or absent and that this phase could be restored in the "prediabetics" by an infusion of theophylline along with the glucose [3] [5]. Other evidence supports the contention that in diabetes an insulin secretion defect specific to glucose exists [6]. Since starvation is also associated with a defect in glucose induced insulin release which can be overcome by theophylline [7] [8], it is possible that the defect in glucose induced insulin release in diabetes mellitus and fasting is similar [8-12]. If this hypothesis is true, then the changes in the glucose induced biphasic insulin response seen in diabetes might also be seen with starvation. Therefore, studies of the effects of $48 \mathrm{~h}$ starvation on glucose induced insulin release patterns in normal human subjects as well as in experimental animals were undertaken.

\section{Materials and Methods}

\section{Human Experiments}

Table 1 presents data in the two groups of subjects studied. The normal group was composed of 12 healthy volunteers with no family history of diabetes mellitus and no glucose intolerance during a standard oral glucose tolerance test. Six were male and 6 female with an average age of 35 (range: $20-64$ ). None were obese (mean percentage of normal body weight according to tables of the Metropolitan Life Insurance Co. : 105.8\%). The diabetic group consisted of 9 males with an average age of 53.2 years (range: $41-62$ ). All were adult onset diabetics; 6 had a family history of diabetes. All were treated with diabetic diets, while 2 subjects also received $1 \mathrm{~g}$ tolbutamide daily until 1 week prior to study. Two of this group were overweight (120\% and $121 \%$ of normal body weight). The mean percentage body weight for this group was 108.1.

The glucose infusion studies were performed in 8 normal subjects and 9 diabetic patients after an overnight fast, and in 7 normal subjects after 48 hours of fasting. The studies were performed in the following manner.

All subjects were maintained on an ad lib diet for at least 1 week prior to testing. Then food was withheld either overnight or for $48 \mathrm{~h}$. The glucose infusion was begun in the morning, utilizing a modification of the technique described by Cerasi and Luft. An in-dwelling needle was placed in the antecubital vein of each arm and kept patent by flushing intermittently with saline and heparin. A priming dose of $0.33 \mathrm{~g}$ of glucose $/ \mathrm{kg}$ b.w. $(26 \% \mathrm{w} / \mathrm{v})$ was injected intravenously within 1 to $2 \mathrm{~min}$. This was immediately followed by a constant infusion of $20 \mathrm{mg}$ glucose $/ \mathrm{kg} \mathrm{b}$. w. $/ \mathrm{min}$ in a $15 \%$ glucose solution $(w / v)$ for $60 \mathrm{~min}$. The rate of infusion was controlled with a Harvard pump. With this infusion, a blood glucose (BG) concentration of approximately $300 \mathrm{mg} / 100 \mathrm{ml}$ was achieved. During the control period for the glucose infusion studies, venous blood samples were obtained $60 \mathrm{~min}, 30 \mathrm{~min}$ and $0 \mathrm{~min}$ before the start of the glucose infusion. After the start of the infusion, blood was sampled every $30 \mathrm{sec}$ for the first 
6 min, every minute from minute 7 to $\min 10$, and at 5 min intervals from minute 10 to min 60 . After the infusion was stopped, sampling at 5 minute intervals was carried out for $50 \mathrm{~min}$. Blood glucose (BG) was measured on the same day of the infusion, utilizing a glucoseoxidase procedure. The rate of glucose disappearance (kg) was calculated by plotting the decay of the blood glucose values on a semilogarithmic scale between 60 and $110 \mathrm{~min}$. Plasma was separated rapidly in the cold and frozen at $-20^{\circ} \mathrm{C}$ for later determination of cals, U.S.A. The perfusions were carried out at pressures of $65-80 \mathrm{~mm} \mathrm{Hg}$ and the flow rates were constant at $7-9 \mathrm{ml}$ per min over the time course of the usual perfusion. Edema was only rarely encountered when perfusions were continued beyond $90 \mathrm{~min}$. Insulin was measured at $30 \mathrm{sec}$ intervals over the first $10 \mathrm{~min}$ and then at 1 min intervals. Since the flow rates were so constant, the insulin was calculated as $\mu \mathrm{U} / \mathrm{ml} / \mathrm{minute}$. The total IRI in Peak I was the sum of the first $6 \mathrm{~min}$ and Peak II of $30 \mathrm{~min}$.

Table 1. Experimental subjects

\begin{tabular}{|c|c|c|c|c|c|}
\hline Subject & Sex & $\begin{array}{l}\text { Age } \\
\text { (yr) }\end{array}$ & $\begin{array}{l}\text { Height } \\
\text { (cm) }\end{array}$ & $\begin{array}{l}\text { Weight } \\
\text { (kg) }\end{array}$ & $\begin{array}{l}\% \text { Ideal } \\
\text { body weight }\end{array}$ \\
\hline \multicolumn{6}{|l|}{ Normals: } \\
\hline WC & M & 38 & 172.7 & 77.7 & 109 \\
\hline $\mathrm{ST}$ & $\mathrm{F}$ & 20 & 157.5 & 54.1 & 105 \\
\hline $\mathrm{LC}$ & $\mathbf{F}$ & 22 & 152.4 & 47.7 & 105 \\
\hline SR & $\mathrm{F}$ & 34 & 170.2 & 60.9 & 102 \\
\hline WK & $\mathrm{M}$ & 64 & 182.9 & 82.7 & 104 \\
\hline $\mathrm{GF}$ & $\mathrm{M}$ & 32 & 182.9 & 81.8 & 103 \\
\hline WB & M & 36 & 185.4 & 84.1 & 111 \\
\hline $\mathrm{AP}$ & M & 30 & 172.7 & 80.0 & 112 \\
\hline$J G$ & M. & 53 & 185.4 & 90.0 & 110 \\
\hline BP & $\mathrm{F}$ & 38 & 137.2 & 57.7 & 98 \\
\hline ME & $\mathrm{F}$ & 36 & 156.9 & 58.2 & 102 \\
\hline \multirow[t]{2}{*}{$\mathrm{JC}$} & $\mathrm{F}$ & 23 & 152.4 & 52.7 & 108 \\
\hline & & $\overline{35.5 \pm 3.6}$ & & & $\overline{105.8 \pm 1.2}$ \\
\hline $\begin{array}{l}\text { Diabetics: } \\
\text { GR }\end{array}$ & & & & & \\
\hline GR & M & 50 & 165.1 & 59.1 & 97 \\
\hline JM & M & 42 & 182.9 & 82.7 & 104 \\
\hline WK & M. & 41 & 175.3 & 81.8 & 112 \\
\hline WV & M & 58 & 167.6 & 64.6 & 104 \\
\hline $\mathrm{FO}$ & M & 55 & 188.0 & 95.5 & 120 \\
\hline SG & M & 62 & 180.3 & 90.9 & 121 \\
\hline RL & M & 51 & 175.3 & 77.3 & 105 \\
\hline SB & M & 57 & 170.2 & 72.7 & 105 \\
\hline \multirow[t]{2}{*}{$\mathrm{CA}$} & $\mathbf{M}$ & 43 & 175.3 & 76.8 & 105 \\
\hline & & $\overline{51.0 \pm 3.4}$ & & & $\overline{108.1+2.7}$ \\
\hline
\end{tabular}

the IRI. For that purpose, a double antibody radioimmunoassay technique was used [13].

Phase I insulin secretion was defined as that portion of insulin released during the first $10 \mathrm{~min}$ of glucose infusion, while phase II is that portion of insulin released over the next $50 \mathrm{~min}$ until the glucose infusion was discontinued. Insulin release was calculated as the increment in insulin level above the basal insulin level. These increments were then totalled for each phase and expressed as $\mu \mathrm{U} / \mathrm{ml} / \mathrm{min}$.

\section{Animal Experiments}

Male Sprague-Dawley rats weighing 350-400 g were studied in the fed or starved $(48 \mathrm{~h})$ state. The fasted animals had no food in their stomachs. Insulin release curves following a glucose stimulus were obtained utilizing isolated rat pancreas perfusions as described by Curry and Grodsky [1]. The perfusate was not recycled. Perfusions were carried out with 70 and $300 \mathrm{mg} / 100 \mathrm{ml}$ glucose in Krebs-Henseleit bicarbonate buffer ( $\mathrm{pH} 7.4$ ) with $2 \%$ human albumin. The albumin was obtained from Cutter Pharmaceuti-

\section{Results}

Fig. 1 compares the insulin and glucose response to the glucose infusion in normal and diabetic subjects. In both groups there was a rapid increase in IRI, with a subsequent fall to about $50 \%$ of peak level within the first $10 \mathrm{~min}$ of infusion (phase I), and slowly increasing IRI levels over the next $50 \mathrm{~min}$.

While the patterns of IRI secretion were biphasic in both groups, there was a marked difference in the amount of insulin secreted (Table 2). The normal group secreted more insulin than the diabetic group in both phases and also secreted more of their total insulin in phase I $(14.3 \%$ vs. $9.3 \%, p<0.025)$.

During the infusion, BG rose in all groups (Fig. 1 and Table 2). During phase I insulin secretion, the mean $B G$ was not significantly higher in the diabetic vs. the normal, while during phase II, the mean BG in the diabetic group was significantly higher $(p<0.05)$.

Fig. 2 shows the response of the 48 h fasted normal subjects to the glucose infusion. The biphasic pattern of IRI release was maintained. However, there was 
A. NORMAL SUBJECTS $(\mathrm{N}=8$ )
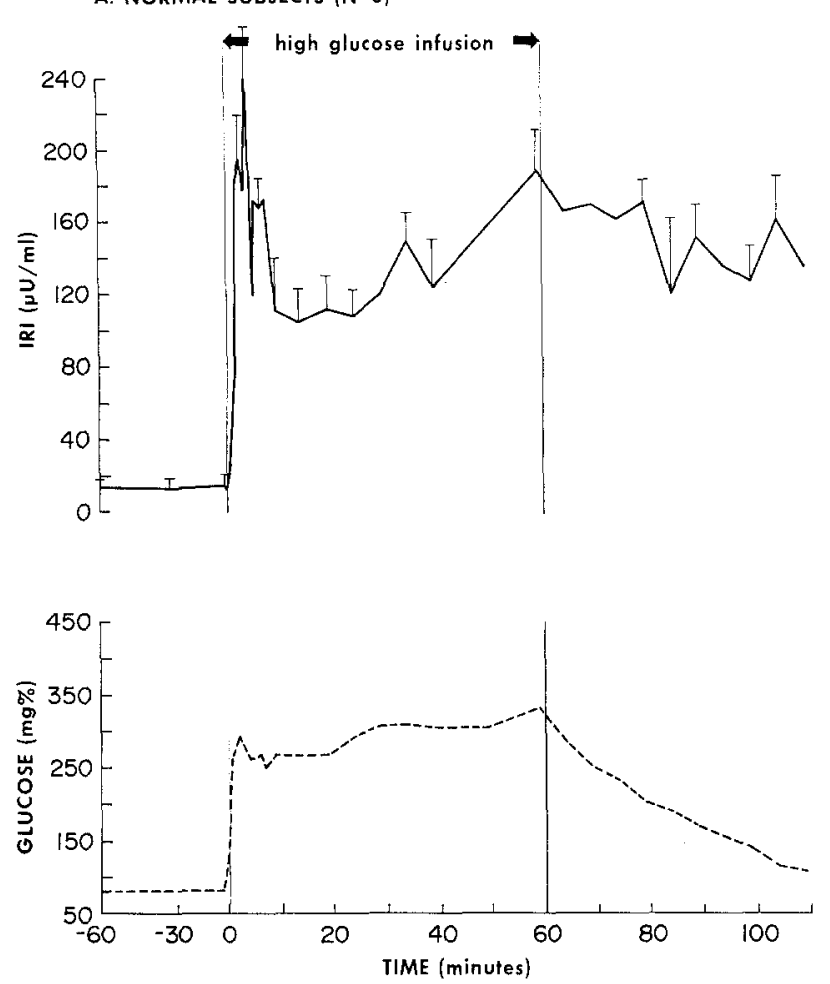

B. DIABETIC SUBJECTS ( $N=9$ )
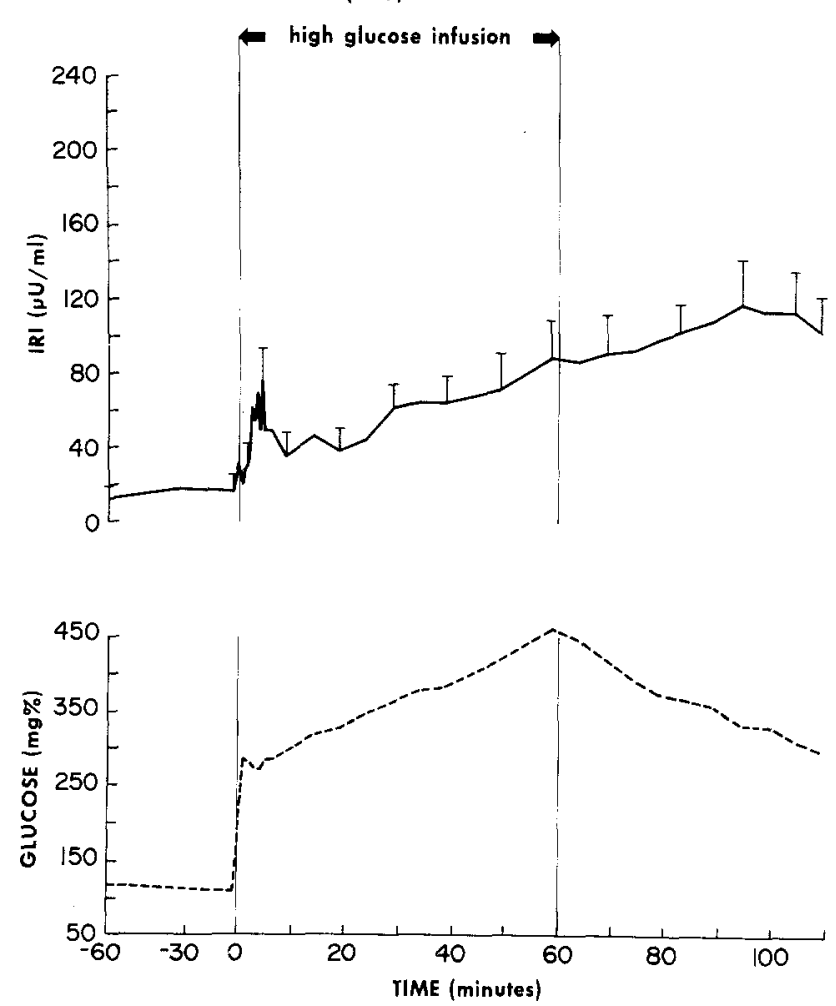

Fig. 1, A and B. The insulin and glucose response patterns to glucose infusion in normal subjects (A) and diabetics (B) less IRI released during phase $I$ and $I I$ compared to overnight fasted normals. However, the amount of insulin secreted in phase I compared to total IRI was no different in the $48 \mathrm{~h}$ fasted compared to the overnight fasted normal subjects $(16 \pm 0.4$ vs. $14 \pm 1.3 \%$, respectively). There was no significant difference in $B G$ levels attained during phase $I$ and Phase $I I$ between these groups.

Comparing the starved normals with the diabetics, it can be seen that the total insulin as well as the phase II insulin secretion were not significantly different from those of the diabetic group. However, phase I insulin release remained significantly greater in the $48 \mathrm{~h}$ fasted normal group $(16 \pm 0.4 \%$ vs. $9.3 \pm 1.6 \%$, $p<0.01$ ). The mean BG levels attained during phase $\mathrm{I}$ and II in the $48 \mathrm{~h}$ fasted group were significantly lower than those attained in the diabetic group.

Table 3 and Fig. 3 show the effects of starvation on insulin release in isolated pancreas perfusions. The total insulin was decreased $(p<0.01)$, as were phases I and II compared with fed control values. In the pancreas of fed animals, phase $I$ insulin release represented $13.1 \%$ of the total IRI released. In the fasted preparations, phase I represented $8.98 \%$ of the total $(p<0.05)$.

\section{Discussion}

The present studies describe plasma insulin patterns following glucose infusions. Although considerable individual variation was encountered in total insulin

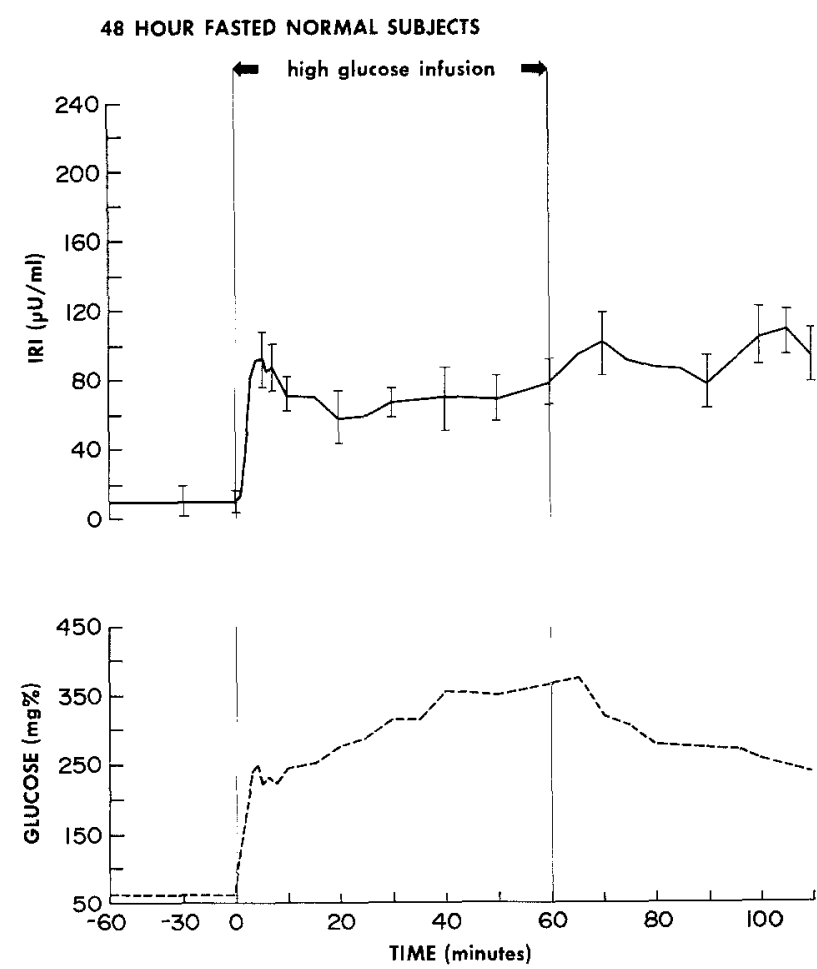

Fig. 2. The insulin and glucose response pattern of 7 normal subjects after a $48 \mathrm{~h}$ period of fasting 
secretion, it should be emphasized that the patterns of insulin secretion in the normal overnight fasted subjects were constant. The decrease in the early phase of insulin release in human diabetics, when compared with non-diabetic subjects, [3] [14-17] has been confirmed. The total insulin secreted by the diabetics was reduced by $61 \%$, while that portion of insulin secreted in phase I was reduced to a greater extent than that in phase II, $76 \%$ and $58.6 \%$ reductions respectively. The findings in normal subjects fasted for $48 \mathrm{~h}$ indicated that they retained a biphasic insulin secretory pattern similar to that of the overnight fasted controls. Although total insulin secreted by the fasted subjects was strikingly decreased $(48.5 \%)$, compared with the controls, both phases (I and II) were decreased equivalently $(43.2 \%$ and $49.1 \%)$.

To deal with the likelihood that this period of fasting in man was not sufficiently prolonged to alter

Table 2

\begin{tabular}{|c|c|c|c|c|c|c|c|c|}
\hline \multirow[b]{2}{*}{$\begin{array}{l}\text { No. of } \\
\text { Patients }\end{array}$} & \multirow[b]{2}{*}{ Subjects } & \multirow[b]{2}{*}{$\begin{array}{l}\text { Phase I } \\
(10 \text { min })\end{array}$} & \multicolumn{2}{|c|}{ Insulin release ( $\mu$ Units) } & \multirow[b]{2}{*}{$\frac{\text { Phase } I}{\text { Total }} \times 100$} & \multicolumn{3}{|c|}{ Blood glucose $\mathrm{mg} / 100 \mathrm{ml}$} \\
\hline & & & $\begin{array}{l}\text { Phase II } \\
\text { (50 min) }\end{array}$ & Total & & $\begin{array}{l}\text { Mean } \\
\text { Phase I }\end{array}$ & $\begin{array}{l}\text { Mean } \\
\text { Phase II }\end{array}$ & $\mathrm{Kg}$ \\
\hline 8 & Normal & $1115 \pm 334^{\mathrm{a}}$ & $6669 \pm 1555$ & $7784 \pm 1854$ & $14.3 \pm 1.3$ & $254 \pm 29$ & $298 \pm 47$ & $2.28 \pm 0.24$ \\
\hline 9 & Diabetic & $278 \pm 106$ & $2760 \pm 576$ & $3038 \pm 659$ & $9.3 \pm 1.6$ & $283 \pm 34$ & $394 \pm 32$ & $0.74 \pm 0.08$ \\
\hline 7 & $\begin{array}{l}48 \mathrm{~h} \text { fasted } \\
\text { normal }\end{array}$ & $632 \pm 104$ & $3374 \pm 654$ & $4006 \pm 757$ & $16.0 \pm 0.4$ & $225 \pm 19$ & $313 \pm 17$ & $0.89 \pm 0.18$ \\
\hline
\end{tabular}

a Mean \pm SEM

Statistical comparisons of the above data. Only significant $p$ values are shown:

Statistical significance of comparison between normals and diabetics. IRI release during phase I ( $p<0.025)$, phase II $(p<0.01), \%$ total IRI due to phase I $(p<0.025)$, total IRI $(p<0.025)$, BG mean phase II $(p<0.05)$ and Kg $(p<0.01)$ Statistical significance of comparison between $48 \mathrm{~h}$ fasted and normals. IRI phase I $(p<0.05)$, phase II $(p<0.05)$, total IRI $(p<0.1 ;>0.05), \mathrm{Kg}(p<0.01)$.

Statistical significance of comparison between $48 \mathrm{~h}$ fasted and diabetics. IRI phase I $(p<\mathbf{0 . 0 5})$, \% total IRI due to phase I $(p<0.01)$, BG phase $\bar{I}(p<0.05)$, BG phase II $(p<0.05)$.

Table 3. Rat pancreas perfusions

\begin{tabular}{llllll}
\hline \multirow{2}{*}{$\begin{array}{l}\text { No. of } \\
\text { experiments }\end{array}$} & $\begin{array}{l}\text { Condition of } \\
\text { animal }\end{array}$ & $\begin{array}{l}\text { Insulin release ( } \mu \text { Units }) \\
(6 \mathrm{~min})\end{array}$ & $\begin{array}{l}\text { Phase II } \\
(30 \mathrm{~min})\end{array}$ & $\begin{array}{l}\text { Total } \\
(36 \mathrm{~min})\end{array}$ & $\begin{array}{l}\text { Phase I } \\
\text { Total } \times 100\end{array}$ \\
\hline 7 & $\begin{array}{l}\text { Fed } \\
\mathbf{4 8} \mathrm{h}\end{array}$ & $2543 \pm 260^{\mathrm{a}}$ & $16922 \pm 2107$ & $\mathbf{1 9 4 6 4 \pm 2 3 0 4}$ & $13.06 \%$ \\
6 & Fasted & $581 \pm 129$ & $3891 \pm 849$ & $6472 \pm 973$ & $8.98 \%$ \\
\hline
\end{tabular}

a Mean \pm SEM ( $p$ values in text)

b Phase II was arbitrarily determined.

Phase I was determined by the typical first peak response which was over at $6 \mathrm{~min}$.

IRI RELEASE PATTERNS-PERFUSED PANCREAS

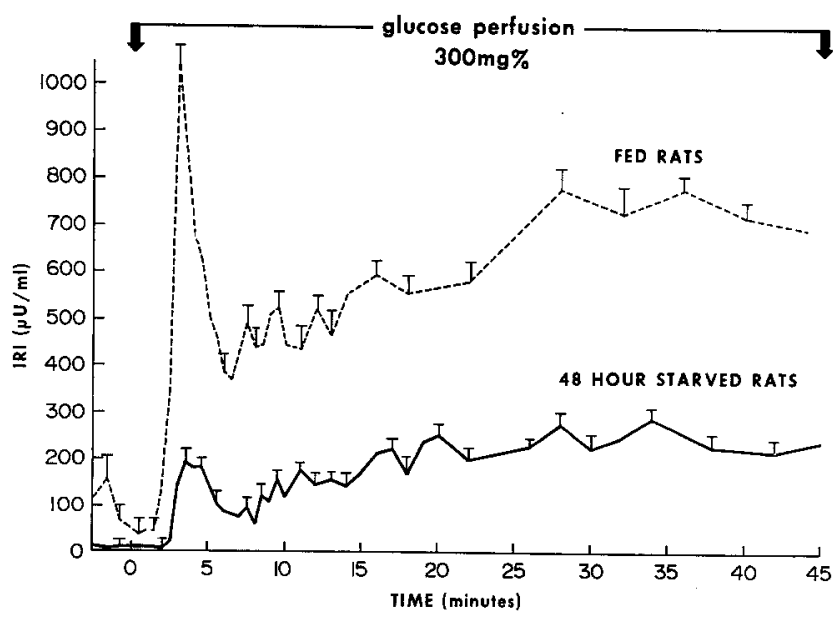

Fig. 3. The insulin response to glucose of isolated pancreas obtained from 7 fed rats compared with 6 rats after $48 \mathrm{~h}$ of starvation the biphasic insulin pattern, experimental animals were studied. Starvation of rats for $48 \mathrm{~h}$ resulted in changes in insulin secretory patterns. Isolated rat pancreas was perfused with $300 \mathrm{mg} / 100 \mathrm{ml}$ glucose and produced a biphasic insulin curve in the control rats, as previously reported [1]. With starvation, there was a reduction in total insulin secretion $(66.7 \%)$, while the phase I insulin secretion was reduced more than phase. II insulin secretion $(77.2 \%$ and $65.2 \%$, respectively). In the open-system pancreas perfusions used, glucose concentration of the perfusing fluid remained constant. Hence, the phase II insulin response was probably less than would have occurred in the intact animal, where a rising blood glucose would probably have occurred in phase II. Such a glucose pattern was noted in fasting humans. Glucose infusion studies in the intact rat would have been of interest, but were not technically feasible.

The above findings demonstrate that $48 \mathrm{~h}$ of fasting in normal human subjects is characterized by a quanti- 
tative reduction in insulin response to glucose. Although quantitative comparisons would be more convincing if the same normal subjects were tested in the fed and fasted state, the data clearly show significant decreases in total insulin in a randomly obtained, fasted group. Despite these changes, the biphasic pattern of response was not significantly altered.

On the other hand, the animal studies indicate that starvation of a prolonged nature does produce a pattern not dissimilar from that in human diabetes. The factors responsible for the altered insulin secretion seen following a glucose stimulus in starved rats are not known, though decreased content of cyclic AMP [18] and decreased adenylate cyclase [19] activity have been reported in isolated pancreatic islets of starved animals. Other factors may well be involved in starvation, such as alterations in glucose-inducible enzymes participating in the metabolism and recognition of glucose as an insulinotropic agent. However, at the present time, there are no definitive data to support these speculations as they relate to patterns of insulin response in starvation. Finally, our observations add an additional parameter to the "diabetic" syndrome of experimental starvation and suggest that there may be metabolic similarities in the insulin secretory defects in diabetes and starvation.

Acknowledgement. Wo wish to thank Miss Nancy Voyles and Mr. Sam Wilkins for their technical assistance.

\section{References}

1. Curry, D.L., Bennett, L.L., Grodsky, G.M.: Dynamics of insulin secretion by the perfused rat pancreas. Endocrinology 83, 572-584 (1968)

2. Kanazawa, Y., Kuzuyn, T., Ide, T., Kosaka, K.: Plasma insulin responses to glucose in femoral, hepatic and pancreatic veins in dogs. Am. J. Physiol. 211, $442-448$ (1966)

3. Cerasi, E., Luft, R.: Plasma insulin response to glucose infusion in healthy subjects and in diabetes mellitus. Acta Endocrinol. 55, 278-304 (1967)

4. Turner, R.C., Schneeloch, B., Nabarro, J.D.N.: Biphasic insulin secretory response to intravenous xylitol and glucose in normal, diabetic and obese subjects. J. clin. Endocrinol. Metab. 33, 301-307 (1971)

5. Cerasi, E., Luft, R.: 'The effect of an adenosine 3 '5' monophosphate diesterase inhibitor (aminophylline) in the insulin response to glucose infusion in prediabetic and diabetic subjects. Hormone Metab. Res. 1, $162-168(1969)$
6. Floyd, J.C., Fajans, S.S., Conn, J.W., Thiffault, C., Knopf, R., Guntsche, E.: Secretion of insulin induced by amino acids and glucose in diabetes mellitus. $\mathrm{J}$. clin. Endocrinol. Metab. 28, 266-276 (1968)

7. Voyles, N., Gutman, R.A., Selawry, H., Fink, G., Penhos, J.C., Recant, L. Interaction of various stimulators and inhibitors on insulin secretion in vitro. Horm. Res. 4, 65-73 (1973)

8. Serrano-Rios, M., Ramos, F., Rodriquez-Minon, J.L., Visanco, F.: Studies in prediabetes. Insulin response to oral glucose, intravenous tolbutamide and rapid intravenous glucose infusion in genetic prediabetics. Diabetologia 6, 392-398 (1970)

9. Grey, N.J., Goldring, S., Kipnis, D.M.: The effect of fasting, diet and actinomycin $\mathrm{D}$ on insulin secretion in the rat. J. clin. Invest. 49, $881-889$ (1970)

10. Malaisse, W.J., Malaisse-Lagae, F., Wright, P.H.: Effect of fasting upon insulin secretion in the rat. Am. J. Physiol. 213, 843-848 (1967)

11. Buchanan, K.D., Vance, J.E., Williams, R.H. : Effect of starvation on insulin and glucagon release from isolated islets of Langerhans of the rat. Metabolism $18,155-162(1969)$

12. Unger, R.A., Eisentraut, A.M., Madison, L.L.: The effects of total starvation upon the levels of circulating glucagon and insulin in man. J. clin. Invest. 42, 1031 1039 (1963)

13. Morgan, C.R., Lazarow, A. Immunoassay of insulin: Two antibody system. Diabetes 12, 115-126 (1963)

14. Soeldner, J.S., Gleason, R.E., Williams, R.F., Garcia, M.J., Bearwood, D.M., Marble, A.: Diminished serum insulin response to glucose in genetic prediabetic males with normal glucose tolerance. Diabetes $\mathbf{1 7}$, $17-26(1968)$

15. Fujita, Y., Seltzer, H.S.: Confirmation of impaired early insulin response to glucose in mild diabetes. Clin. Res. 21, 42 (1973)

16. Colwell, J.A., Lein, A.: Diminished insulin response to hyperglycemia in prediabetes and diabetes. Diabetes 16, 560-565 (1967)

17. Cerasi, E., Luft, R.: Insulin response to glucose infusion in diabetic and non-diabetic monozygotic twin pairs genetic control of insulin response. Acta Endocrinol. 55, 330-345 (1967)

18. Selawry, H., Gutman, R., Fink, G., Recant, L.: The effect of starvation on tissue adenosine 3 ' -5 ' mono. phosphate levels. Biochem. Biophys. Res. Comm. 51, 198-204 (1973)

19. Howell, S.L., Green, I.C., Montague, W.: A possible role of adenylate cyclase in the long-term dietary re gulation of insulin secretion from rat islets of Langerhans. Biochem. J. 136, 343-349 (1973)

\author{
Dr. L. Recant \\ VA Hospital \\ Diabetes Research Laboratory \\ 50 Trving Street, N.W \\ Washington, D.C. 20422 \\ U.S.A.
}

